Will Sexual Robots Modify Human Relationships? A Psychological Approach to Reframe the Symbolic Argument

Piercosma Bisconti

Dirpolis Institute, Sant'Anna School of Advanced Studies, Pisa, Italy

piercosma.biscontilucidi@santannapisa.it 


\title{
Will Sexual Robots Modify Human Relationships? A Psychological Approach to Reframe the Symbolic Argument
}

\begin{abstract}
The purpose of this paper is to understand if and how interactions with Sexual Robots will modify users' relational abilities in human-human relations. We first underline that, in today's scholar discussion on the "symbolic argument", there is no theoretical framework explaining the process of symbolic shift between human-robot interactions (HRI) and human-human interactions (HHI). To clarify the symbolic shift mechanism, we propose the concept of objectual mediation. Moreover, under the lens of Winnicott's object-relation theory, we argue that HRI can structurally modify users relationality, degrading intersubjective abilities: Sexual Robots may blurry the limit between the "internal object" and the external one. We conclude that, under certain conditions, interactions with Sexual Robots may bring the user back to an infantile object-relation setting, worsening the user ability to manage relational frustration. This will negatively impact on human-human interactions and social values in general.
\end{abstract}

Keywords: sexual robots, social robots, human-robot interactions, companion robots, philosophy of technology, psychology, object-relation theory, Winnicott, Psychoanalysis

\section{Introduction}

Sexual Robots (SexRs), today mainly with a female aspect, aim to reproduce as credibly as possible a human sexual interaction (1). They try not only to replicate the physical aspects of a sexual intercourse, but also the relational and emotional ones. There are some examples of Sexual Robots on the market yet, although in an early stage (2).

These robots can interact physically and verbally with users, using a predefined set of behaviours (3). The starting point of the scholar discussion about Sexual Robotics could be placed in Levy's book "Love and Sex with Robots" (4) where the author analyses the nature of human sexual interactions in comparison with human-robot sexual interactions. His conclusions are enthusiastic about the introduction of this technology. After that, the interest for Sexual Robotics spread out in the scientific 
literature. The main concerns are about the possibility to rape a SexRs (5), the commercialization of children SexRs (6), the legal rights of SexRs (7), their moral status (3). A very relevant topic of discussion is the social impact of this new technology: SexRs may change the notion of sexual consent and the social representation of women.

In fact, most of the commercialized sexual robots are, today, female (8) and this trend may probably persist for a long time. In many scholars' opinion, the possibility of freely using a robotic female body and performing degrading or violent practices on it could modify the social representation of women (9). The discussion about Sexual Robots is faceted and with a large variety of opinion. On one extreme, some argue that rape and violence will decrease (10), sexual satisfaction of users will increase (11), it will contribute to the reduction of prostitution (11). On the other side, some claim they will contribute to increase violence (12) and that they will reproduce existing gender disparities $(8,9)$. In the middle of these two extremes, most of the scholars take a median position on these topics, when discussing Sexual Robotics.

In this paper, we provide a psychological ground to the symbolic argument. Given the complexity and heterogeneity of this topic, under an object-relation psychological approach we suggest how and why human-SexR relationships may impact on human-human relationships. Before this, we retrace the actual symbolicapproach argumentative structure by emphasizing the inconsistency, as formulated today, of the "consequential claim", namely the belief that Sexual Robots users will transfer socially unacceptable behaviours into human relationships. We will mainly deal with the positions of Richardson, Gutiu and Danaher because they are, in the authors opinion, the most relevant for the discussion about the symbolic-consequences argument on Sexual Robots. There are many other approaches to the analysis of Sexual 
Robots impact in the literature; notwithstanding that this work focuses on this particular type of analysis of the Sexual Robotics issue. In the second part of this work, we propose a psychological systematization of the deviant element of user-SexRs relationship in the light of Winnicott's theory. We discuss the dysfunctional objectrelation that HRI may produce and its effect on users relationality. We claim that a symbolic shift can occur if, and only if, the relation between the subject's desire and the object is not mediated by social channelling or symbolic displacement, concepts that we discuss in the next pages. We conclude that the risk that Sexual Robots will produce objectifying and dysfunctional relational patterns is urgent and real.

\section{The Symbolic Approach}

Among the various existing approaches to understand the possible effects of Sexual Robots on individuals and societies, the so-called "symbolic approach" is one of the most popular (13). This approach analyses human-robot relations acceptability enquiring the possible consequences on socially shared practices and human-human relations. The basic claim is that the actions carried out within human-robot interactions (HRI) will produce consequences in all the other relationships entertained by the user, influencing her social and relational environment. Primarily, what is expected to happen is that HRI relational practices can be transferred into human-human interactions (HHI). The symbolic argument responds to sexual robots supporters who argue that, in HRI, whatever happens in the interaction no one is damaged. In fact, since the robot is not a subject but an object, at least at the current state of technology, is not liable to be harmed either physically or morally. To this claim, the "symbolic argument" supporters reply that the harmed one is the society in general: its values and shared practices. Moreover, also the user is harmed, since her behaviours gradually becomes socially unacceptable: the morally illicit action performed by the user in HRI slightly (but 
inexorably) changes user's social and relational practices.

At the root of the symbolic argument, there is a socio-relational approach to technology: not only does the technological artefact assume a certain value depending on the context (social, cultural, religious), but also the context is modified by the introduction of an artefact (14). This co-implication between context and object, which constantly modify one another, suggests interpreting social, philosophical and cultural issues not only from the partial point of view of one of the horns. A socio-relational approach examines the systemic nature of socio-technical contexts. The symbolic argument is therefore concerned not with the damage that can affect the robot, but with the modification that affects society as a system of relationships, which are coimplicated and co-influenced.

\section{The Consequential Claim}

One of the biggest problems is understanding why and how this symbolic shift between HRI and HHI occurs, how robots can modify socially shared values. Danaher (13) identifies the common structure of all the symbolic arguments in these three points:

(1) "Sex robots do/will symbolically represent ethically problematic sexual norms. (Symbolic Claim.)

(2) If sex robots do/will symbolically represent ethically problematic sexual norms, then their development and/or use will have negative consequences. (Consequential Claim.)

(3) Therefore, if the development and/or use of sex robots will have negative consequences, we should probably do something about this. (Warning Call Conclusion)"

It is evident that the problematic part of the symbolic argument is mainly in the second 
point. In fact, point 1 states something on which there is no disagreement: the act of rape or child sex abuse are, in themselves, unacceptable practices. Point 3 simply makes clear the fact that if the introduction of the SRs is harmful to society, it will be necessary to take measures in this regard.

Instead, point 2 claims that the interaction with Sexual Robots can actually have consequences in user's human relationships and on social values. However, this statement is not at all obvious at all. In fact, it is widely questioned by Sexual Robots supporters, at least in these two ways.

- Instead of worsening users' sexuality, sexual robots could improve it. For example, rapists, if they had the opportunity to marginalize their violent fantasies on Sexual Robots, could exorcise and appease aggressive instincts on SexRs, therefore be less inclined to perform non-consensual acts of violence in daily life. The same goes for child sex abuse. Similarly, the phenomenon of prostitution would decrease (11) since would be replaced by robots.

- 2) There are numerous examples of how this shift between "virtual" and "social" reality does not occur, such as the concerns raised in the early 2000s regarding the use of violent video games. In fact, it was expected that a constant exercise of violence in videogames would increase violent acts outside videogames. As some claim $(15,16)$, this did not happen.

On the contrary, the "Consequential Claim" argues that adopting unacceptable behavior within a given context leads subjects to extend the same behavioural mechanics outside of this context. It is not difficult to think of the many examples of this dynamic, such as violent or sexist behaviour. 
There seems to be an equivalence between these two positions. None of the two brings arguments explaining why in some cases this symbolic shift occurs and in which cases it does not. In our opinion, this equivalence originates from a lack of conceptualization about the dynamics of symbolic transfer.

In the next pages, we analyse some symbolic arguments brought against Sexual Robots and we underline the theoretical impasse: none give a precise account of under which conditions the symbolic shift occurs.

\section{Against Behavioural Automatism}

In the ones who embrace the symbolic approach, there seems to be the implicit belief that humans act exclusively through behavioural automatism, so that if a certain practice (sexual, cultural) is performed a certain number of times, this will become an automatism of the subject, regardless for the context or the dynamic in which it originated.

For example, in her argument Gutiu (9) claims that, since SexRs reproduce patriarchal and sexist sexual norm, they will also socially normalize these norms. In her paper, Gutiu does not explain why sexual practices performed Sexual Robots should then shift into human-human relationships.

The assumption of behavioural automatism, largely implicit, is not convincing as it cannot explain why the shift does not happen in fictional contexts, or in the case of video games. This is the main limitation of theories based on virtue ethics, such as the argument of Peeters \& Haselager (17): the symbolic world of humans is considered to be ruled by automatic reflexes of a-contextual symbolic transfers. It seems that Gutiu, 
and also Peeters \& Haselager, supports that any type of practice in any context can influence social values in general.

To clarify the limit of these theories in explaining the symbolic shift, we formulate the example of the theatre performance.

If an actor on stage impersonates an evil murderer, even though repeating this part every day for weeks, hours and hours a day, although a certain degree of identification is required for a convincing actor performance, he will not become a murderer, nor will visibly increase its aggression in real life. Likewise, viewers who look at the representation of violence, rape, immoralities of various kinds, will not introject this symbolism into their social rules. So, the person who performs the actions, the actor, will not transfer the behavioural patterns out of the fictional context of the play; viewers will not assimilate a symbolic universe made of violence and immorality. Why does the shift not happen in this case? Gutiu's and Peeters and Haselager's arguments cannot address this question.

The second part of this paper will answer this question, namely why in certain context the shift happens, while in others not. Human behaviour is much more complex than a behavioural automatism. Therefore, we believe that the "consequential claim" should be specified and amended with a more convincing conceptualization that explains (if and) why the case of the SexRs does not match the one of the theatre play.

\section{Richardson: Should We Campaign Against SexRs?}

The position paper by Kathleen Richardson (18) is certainly one of the most important in the debate on Sexual Robotics. In her paper Richardson discusses Sexual Robots acceptability criticizing the position of Levy (4), who claims that the relationship with SexRs is equal to the relationship that clients establish with sex-workers. 
Levy's aim, in the equation between SexRs and prostitution, is to bring the phenomenon of Sexual robots back into the wake of a practice as old as patriarchy, that of purchasing sexual services, to normalize this new relationship. On the other hand, he argues that SexRs will supposedly lead to a tendential decrease of human prostitution (and therefore also of the abuses deriving from sex trafficking). In short, for Levy, Sexual Robots are nothing new, having sex with them is not different from prostitution, at most they could improve the situation by reducing human prostitution (and therefore the related abuses).

Richardson dispute Levy's position claiming that the sexual relationship established by a man (given that the most part of prostitution clients are male) with a sex-worker is morally unacceptable because it is degrading and objectifying for the woman. The sex-worker is no longer seen as a human being, but as an object to exploit for (sexual) benefits. The total absence of empathy and respect for the other human makes this relationship morally unacceptable. Since SexRs reproduce the same dynamic as the sexworker-client relationship, therefore SexRs must be banned (or in any case "we must campaign against them").

\section{First Issue: the Equation Between Prostitution and SexRs}

In addition to the criticism pointed out by Danaher (13), we underline two other issues in Richardson's argument. First, Richardson implicitly accepts Levy's analogy between the sexworker-client relationship and the human-SexRobot relationship. This analogy is not questioned but given for granted and evident. Danaher too does not criticize the analogy itself but merely claims that the negative version offered by Richardson does not reflect the complex multiplicity of the client-sexworker relationship. 
Instead, we argue that human-SexRs relationship structurally differs from the sexworker-client one. We believe that human-SexR relationship is much more problematic and consequence-bearer for users' relational setting.

In the client-sexworker relationship, in fact, there are three elements absent in the case of SexRs:

- There is an agreement between client and sexworker that implies at least some recognition of the subjectivity of the other.

- What is feasible or infeasible is clearly formalized by the agreement (if violated, it becomes rape). This formalization implies that the client renounces to the phantasy of total availability of the other, renouncing to a total objectification of the other subject.

- The being available (as an object) of the sex-worker is therefore only fictional, since it applies only within what was decided at the time of the agreement.

We claim that the objectification of the sex-worker is bounded by the agreement made before the beginning of the sexual interaction, within a "contractual" context: the client will pay a certain amount in order to "legitimately" (under an agreement) objectify a body and perform certain sexual practices for a determined amount of time. ${ }^{1}$ What the

\footnotetext{
${ }^{1}$ It is actually disputed in the sex work literature if we can describe the client-sexworker relationship as "contractual". In fact, as Lori Watson points out, understanding sex-work under a contractual framework might be pragmatically irrelevant; also from a theoretical point of view she underlines that it should be understood as an unilateral contract [35]. Although this is a highly valuable discussion, here we are not concerned with the actual ability of the prostitute of making a choice, contractual or not, but with the perception of the
} 
payment is due for, in the sexual exchange between sexworker and client, is precisely the definition of a context (and then a definition of restraints) in which the client is free to treat the sex-worker as an object. Therefore, we highlight two key aspects.

First, the concept of mediation: the objectification of the other's body is allowed under an intersubjective agreement that imposes precise restraints.

Second, the concept of fictionality: the sexworker is not really under the client's will, the agreement creates a fictional context where the client can pretend that the other human being is at his complete disposal.

Anyhow, our considerations describe the sexworker-client relation only at the interactional level experienced by the client, not the subjective situation of the sexworker. We want to emphasize that, at the level of interaction experienced by the client, the case of prostitution implies a certain degree of renunciation to a completely arbitrary (and therefore completely objectifying) use of the other's body.

Therefore, the case of Sexual Robots must be reframed outside the analogy with prostitution: in fact, in the relation with the SexR, the user does not need any mediation on the admissible sexual practices. In this sense, it is much closer to the case of rape, in which the objectification of the other's body is absolute, and no kind of intersubjective bargaining mediates the user's desire. In the case of client-sexworker, the relational intersubjectivity must be assumed in order to fictionally abolish it in the objectifying sexual interaction. In the case of SexRs there is no need to bargain.

client toward the relation. Circumscribed to this, we believe that the client has to bargain with another subject the acceptable sexual practices, thus coming to terms with the fact the other is not a disposable object. 
Moreover, it is doubtful whether the element of fiction remains. In fact, if the user's sexual fantasy concerns another human, symbolized by the Sexual Robot, there may be a degree of fictionality, depending on SexR's ability to simulate a "natural" human interaction. If, instead, there is a fetishization of the machine, and therefore it is precisely the fact that that machine is totally available that produces sexual arousal, there is no fictionality.

In conclusion, we believe that both Levy, when he positively supports the analogy with prostitution, and Richardson, when she underlines the negative side, are wrong. The equation between user-SexRs and client-sexworker relationships is untenable. In fact, the former is characterized by the total absence of limits to the objectification of the other since the element of mediation is totally absent.

\section{Second issue: Justification of the "Consequential Claim"}

Furthermore, in Richardson's argument the "consequential claim" is not supported by any kind of theorization. In fact, she writes:

\footnotetext{
The way that human attribute meanings to robots, nature and animals reflect back to us what is of value. But where do the fantasy images and products come from? Is fantasy just a neutral domain that is a sphere separated off from the 'real' and therefore unproblematic? I propose that fantasy, and the ways that robots are seen show human relations at work. The question is not do humans extend their lifeworlds into robots but what is being transferred to the robot? (18)
}

But this mechanism explains according to which socially constructed phantasies robots are designed, while it says nothing about why "sex robots will further reinforce relations of power that do not recognize both parties as human subjects".

The two issues are distinct: one concerns the symbolic movement that drives from society towards robots, producing their design from social symbols. On the other 
hand, the shift from human-robot relationships back into the human socio-symbolical framework is quite different: the very opposite movement. An identical flaw can be found in the parallel discussion on empathy: moving from the consideration "those who go to prostitutes lack empathy" to "the structure of prostitution encourages empathy to be effectively turned-off' is a fallacy, specifically an affirmation of the consequent. Moreover, in the references that Richardson points out to her other works $(19,20)$, she does not clarify the process that should lead HRI to affect HHI. Obviously, the absence of theoretical support for the consequential claim makes Richardson's whole argument, and therefore also her campaign to regulate/prohibit sexual robots, less effective. In fact, her argument is exposed to the criticism of those who argue that SexRs will not change societal norms.

\section{Addressing the Shift Mechanism Issue}

In the end of his traction of the symbolic argument, Danaher (21) concludes that the consequential claim cannot be supported on a theoretical level. There is, in his opinion, no way to predict whether or not the Sexual Robots can activate the "symbolic consequence". Therefore, the only measure to take is a strong caution and consider Sexual Robots as a social experiment, following the theoretical approach of Van De Poel (22).

In conclusion, none of the theories discussed so far theoretically justifies the validity of the consequential claim. Everyone agrees that in some cases the shift occurs, but it does not seem possible to understand precisely in which cases it happens.

In this chapter, we present a theoretical framework, supporting the symbolic argument, that: 
- Offers a clear explanation of the mechanism that can activate the symbolic consequence, overcoming the epistemic equivalence between the various forecasts on Sexual Robots and clarifying the reasons why they will produce a transfer of relational patterns from HRI to HHI (the "Shift Mechanism Issue")

- Explains what modification of the user's relational behaviours occurs in HRI, and which is the symbolic content transferred to HHI ("Symbolic Content Issue"). Regarding this second point, we clarify what we expect to be changed in HHI due to interactions with Sexual Robots. The arguments discussed so far are mostly moralistic and deal with anecdotal elements: namely if SexRs will be able to increase or decrease sexism, rape, child sexual abuse, as if all these elements were unrelated to each other. Instead, we suggest that SexRs may cause a general modification within the user's psychological-relational structure: a framework for a systematic discussion on the topic of Sexual Robots, and perhaps for Social Robots in general.

In this chapter, we support the position that the "symbolic-consequences argument" can only apply on condition that, in the context in which unacceptable practices are performed, the element of objectual mediation is not present or it is strongly reduced.

\section{Objectual Mediation of Desire}

We define a context "mediated" when it presents a set of formal constraints, which limits or channels the will and action of the individual, when relating with an object. These rules can emerge from an agreement or from an unchangeable condition of the context itself.

In the second case, individuals must cope with some intrinsic limitation of the object in order to reach satisfaction of their wills: if I am thirsty in the desert and I have 
only one bottle of water, I must ration my use of water. In this case, the context or the object itself forces to limit or postpone the satisfaction of the desire, therefore requiring frustration management (23). On the other hand, when the objectual mediation is produced by social agreement, the role of constraints is to avoid that individuals may perform socially unacceptable acts. By channelling impulses within the context rules, subjects have the opportunity to release the weight of the drive by acting within a socially acceptable frame, when relating with the object. Therefore, in an intersubjective social context, individual must renounce to the idea that she can dispose of the external world. An example of a social limitation is a cue in a museum: in order to enter the place, I must wait standing in the line. In this case I must manage a frustration (standing in the cue) in order to satisfy my desire (see the museum). Apart from limiting individuals will, social mediating elements channel the individual drive to allow a socially acceptable satisfaction: for example extremely formalized games that channel individuals violence, such as boxing or martial arts. In the relationship between sexworker and client, the client's sexual drives are channelled by an agreement on what is acceptable or not. This element clearly distinguishes the relationship between sexworker and client from rape, in which there is nothing limits or channels the rapist drive. When the drive is not mediated the other subject is treated like an object, therefore no intersubjective relationship takes place (26). If this process of social mediation of drives does not take place, the individual shows an objectifying behaviour.

The process of conveying aggressive and sexual drives within ruled contexts, in order to hold back the objectifying behaviour and act in a socially acceptable way, is typical of the child development of intersubjective relations (24). Symbolic and metaphorical worlds are built during children games, in which the satisfaction of a (otherwise non-socializable) drive is allowed only within the rules of the game (25). In 
the child's relationship with the world, the renunciation to an objectifying omnipotence occurs only thanks to the normative mediation of the parents, and allows intersubjectivity (26).

Another fundamental element that mediates the relations between the subject and the realization of a drive is the fictional realization: in this case the impulse is displaced from its original target (the object) to a symbolic representation of it (the symbol): this allows an imaginary satisfaction of drives (24). In the realm of imaginary satisfaction, the subject is not bound by social mediation and no frustration management is required: in phantasies the external world is at the full disposal of the subject (26). Still, a mentally healthy individual is aware that the action is performed on a symbolic substitute, not on the original target. For example, a person who rips off the photo of an ex-partner deploys his/her aggressive drives on a symbolic substitute, still aware that the symbolic aggression will not affect the represented individual. Even though, symbolic enacting partially discharges the drive tension in an acceptable way.

Hence, we can distinguish three types of mediations: the intrinsic objectual limitation, the social channelling and regulation of drives, the symbolic displacement. If on the one hand the first characterizes any objectual or intersubjective relation, the last two are peculiar of intersubjective relationship. If the social mediation decays, the drive of the subject can no longer be channelled and managed intersubjectively. Martial arts turn into a fight, the relationship between client and Sexworker becomes rape.

In the case of symbolic displacement, if the distance between the symbol and the object becomes blurry the antisocial behaviour might no longer be satisfied only in a representative way on the symbolic object. In order to maintain a symbolic reference, which preserves the distance between object and symbol, it is necessary that the symbol and the original object of the impulse are clearly different. If fictionality gradually 
decays, the drive may leave the space of symbolic satisfaction and it becomes unleashed into reality. For example, the more belonging to a football team acquires importance outside the context of the game, the more the aggressive drive (which was previously symbolically managed inside the stadium) turns out to be all-encompassing and the resulting violence escapes from the context of football rivalry.

Now we can draw some preliminary conclusions on the "shift mechanism", at the core of the symbolic approach.

- First, we assume that for the user the SR is a symbolic representation of a human being, and that therefore the real objective of the sexual drive is not in the robot itself, but in the human being, symbolically represented (27) .

- We conclude that the more the interaction with the SR is mediated, the more the symbolic shift mechanism will be unlikely to happen. In fact, the three types of mediation (intrinsic, social channelling, symbolic displacement) force the drive into a formalized and ruled satisfaction. In the absence of this channelling, the subject behaviours enacted to satisfy the drive are more likely to shift outside the HRI. The distance between the symbol (the SexR) and the represented subject (the human being who, on an imaginary level, is the object of fantasy) should prevent the symbolic shift.

From this theoretical ground a regulatory framework can be deduced. For example: it would be better if SRs could be used only in places specifically thought for this kind of entertainment, than sold to private individuals. This because the creation of a ruled and clearly separate place from individuals' houses will maintain the fictionality of the sexual experience, in respect to the human-human interactions it refers to. Moreover, as already proposed (17), Sexual Robots should have some kind of consent module so that, 
if the sexual interaction becomes violent or a simulation of a rape, the robot should simply stop being interactive.

We conclude that the shift mechanism happens when there is no mediation in the satisfaction of a desire. This claim explains why in the case of theatre performance no symbolic shift happens while in other cases it does. The limitation, social channelling and symbolic displacement of the drive satisfaction can be a framework to evaluate Sexual Robots admissibility.

\section{Addressing the Symbolic Content Issue}

After discussing the shift mechanism issue, a fundamental part of the discussion on Sexual Robots focuses on understanding what is the peculiar element at the roots of HRI, producing the unacceptable behaviours that would be performed on Sexual robots. There are two concerns on the relationship between users and SexRs:

- That subjects who already have sexually unacceptable tendencies can normalize them on Sexual Robots, as for example in Gutiu (9).

- That subjects can develop sexually deviant behaviours because of the relationship with Sexual Robots, as for example in Richardson (18).

The two questions, which at first sight are similar, involve completely different theoretical issues. In the first case, HRIs are not problematic per se, but are only the place where individuals' deviant behaviours are expressed and strengthened. The answer to the first question completely depends on the "consequential claim" issue, namely in which cases and for what reasons the symbolic transfer occurs. In this case, the robot has no value in itself, but only as a symbol. As for the second question, it implies that the relationship between human and robot could produce deviant mechanisms in itself. 


\section{Robots Between Subjectivity and Objectivity}

We support this last hypothesis. So, we formulate this question: assuming that the symbolic shift mechanism is operative, how will the HHI change because of HRI, assuming a user with no previous deviant sexual behaviours?

In part, this element has already been discussed throughout the paper, when analysing the concepts of objectifying relationship and frustration management.

First we identify, with Turkle et al. (28), a characteristic essentially distinguishing HRI from HHI: the robot is always and unlimitedly available. This is how we understand the concept of "object availability": an object that one can arbitrarily dispose of, without the need to bargain desire and drives enacting and without the experience of any type of frustration, except for the intrinsic limitations of the object. This is a fundamental difference in respect to human relations, where the availability of the other individual is uncertain and, in any case, not total.

Nevertheless, unlike objects, the robot is responsive. In this case, being fully available to the user is not a simple objectual passivity, as any other object that a human owns: Social Robots mimic intersubjectivity, they are responsive, engaged in interactions (29). Then, the robot has an objectual characteristic, unlimited availability, and a subjective one, responsiveness.

Therefore, interactions with Social Robots (and SexRs too) are situated in the middle of the two possible relations: objectual and intersubjective. In psychological terms, in the former the subject disposes of the object. In the latter it is necessary to come to terms with the fact that the other subject can act in a way that does not conform to expectations and desires $(23,25)$, therefore producing frustration. The Sexual Robot is in an intermediate position between a subjective and an objectual relationship.

\begin{tabular}{|l|l|l|}
\hline Objectual relation & Object is at disposal & Object is not responsive \\
\hline
\end{tabular}




\begin{tabular}{|l|l|l|}
\hline Intersubjective relation & $\begin{array}{l}\text { Object is not at } \\
\text { disposal }\end{array}$ & Object is responsive \\
\hline Human-robot relation & Object is at disposal & Object is responsive \\
\hline
\end{tabular}

SexRs produces a simulated intersubjective relationship where the user desires are always satisfied and in no case is relationally frustrated. Human intersubjective relationships (unless dysfunctional) prevent an individual from experiencing a relation where no bargain or frustration management is required (26). The (simulated) intersubjective relationship with SexRs instead precisely fulfils this phantasy: that the other subject is completely available to user's desires and drives.

Therefore, we claim that the symbolic content that may be shifted between HRI and HHI is the expectation of an objectual availability of other subjects. This may end up in a reduction of users' ability of relational frustration management. The objectual availability, that pertains to objectual relations, is transferred in the intersubjective relations through the SR. If the expectation of objectual availability enters in the realm of intersubjective interactions, this may shift to HHI, if nothing mediates and distinguishes HRI from HHI. In fact, today only the intrinsic limitations of SRs (their poor human resemblance, speaking and understanding abilities, sensorimotor skills) impede the symbolic shift mechanism.

Nevertheless, these are limitations that, thanks to the engineering improvements of robotics, will be supposedly reduced in the next years. Then, seems to be necessary to include other types of limitations in order to avoid the symbolic shift.

\section{Internal and External Objects}

We must provide theoretical support for these statements. Why is the subject forced to curb aggression and to manage desire frustration in intersubjective relationships? 
Winnicott, in "On the Use of the Object and Relating through Identifications" (30), gives an account of the different ways subjects enter into a relationship with the external world, to explain according to which mechanism children develop adult object relationships and functional intersubjective relationship.

This shows the passage, in the child, from "relating" with an object to "using" it. The first modality concerns the infantile stage while the second one marks the passage to a more mature setting, which leads to intersubjectivity.

In the case of "relating", the "object" is produced within the inner world of the child. It means that the internal object imagined and the external object, independent from the subject's will, are not yet distinct in the subject's representation $(31,32)$. For example, in the infant experience the mother's breast is not configured as an object clearly separate from the baby (32). Then, objects of phantasy and external objects are not distinct in a first stage. The "use" of an object, on the other hand, presupposes the recognition of the object independence and produce a separation, in the individual's mind, between the internal object (imaginary and fully available) and the external object (independent and often cause of frustration).

Another work used Winnicott psychoanalysis in order to understand the humanrobot sexual (or in any case intimate) relations (33). In this work the author analyses the relation between a man and a female-looking doll in therapeutic sessions. The author of the paper interprets the psychic role of the sex doll under the concept of "transitional object", namely the attachment to an object that, for the subject, is partially part of the phantasy and of the reality. We will deal with the different problem of the management of frustration and aggressivity in the difference between relating and using, underlining the concept of the object "residuality" as the core device for the establishment of a functional intersubjectivity. 


\section{The Residual Object}

How does this transition from "relating" to "using" takes place? Winnicott (30) claims that when an object does not respond to the child desires, namely does not adapt to phantasy, the aggressive impulse deploys: the external (not phantasy-conformed) object must be destroyed in order to restore the child's imaginary dominion over reality.

If this destruction succeeds, namely the object is modified by the aggressive behaviour, the child will not distinguish between the imaginary internal object and the external one, therefore an objectifying behaviour persists. When the destructive attempt fails (parents neither align to child's aggressive requests nor respond aggressively), the split between the internal and external object takes place. This happens because the child's aggressiveness, omnipotent over the internal object, does not affect the external one, then this last must be recognized as something different from the internal. Therefore, the external object takes the form of a non-objectifiable residue of the imaginary object. This external residual object, on which aggression had no effect, is precisely what puts the grounds for intersubjective relationships, accustoming the child to manage relational frustration. In fact, in intersubjective relationships the subject must manage the frustration produced by the "alterity" and unmanageability of the other individual, often not conforming to the subject's desires (26).

Our claim is that the relationship between the user and the Sexual Robot precisely reverses this process. In the adult, with a functional relationality, the separation between internal (imaginary and fully available) and external (residual and independent) object is clear, producing a limit to objectifying dynamics $(23,26)$. The Sexual Robot, thanks to its ability to actively engage into a relationship with the user, simulates an intersubjective relationship which, however, does not allow the establishment of a "use" relationship. It does not originate an object-residue but instead 
adapts perfectly to the subject's imagination. This may gradually degrade the individual's awareness on the difference between the internal object and the external object.

In conclusion, the risk of sexual HRI is the possibility that users extend the objectual relational setting on subjects. The dynamic that arises in HRI reproduces the infantile setting of intersubjective relationships, namely the attempt to reduce the world to phantasy (30), in order satisfy the subject's desire without the need of frustration management.

Therefore, from a psychological point of view the mediation criteria can be described as the constant negotiation between phantasy and reality required to a subject. The more the subject must renounce to an imaginary drive satisfaction, the more frustration she/he has to manage. The more intersubjective reality adapts to phantasy, the more the subject gets used to behave towards other individual in an objectifying setting.

\section{Conclusions}

Sexual Robots may not only normalize socially unacceptable behaviours of subjects with already deviated sexual behaviours. As discussed, the user-SexR relationship may produce a dangerous relational dynamic, which may gradually transpose the expectation of objects availability in subjects availability. It mixes objectual relations with intersubjective ones. The more robots reproduce human relationality, the greater this concern is.

This article was intended to clarify two blurry aspects of Sexual Robots scholar discussion: 
- Why HRI will have effects on HHI (consequential claim) and according to what dynamics it occurs.

- What is the HRI dysfunctional element that may be transferred, and how it modifies HHI.

We answered the first question differentiating the cases in which the symbolic shift occurs and those in which not (the shift mechanism issue). We concluded that the element regulating the happening of a symbolic shift is that of drive mediation. We highlight three way in which the drive may be mediated: the intrinsic objectual limitation, the social channelling of drives, the symbolic displacement. Regarding Sexual Robots, only the first level of mediation takes place: due to the functional limitations of today's Sexual Robots in resembling a human sexual interaction a symbolic shift seems to be unlikely to happens due to intrinsic objectual limitations. These limitations are likely to be overcome in the next years. Therefore, it is necessary to regulate Sexual Robots and introduce design criteria preventing the symbolic shift. Though, the aim of this paper is to offer a theoretical framework to understand the mechanism of symbolic shift, next works will deal with design proposals.

Regarding the second question, under the lenses of Winnicott's theory, we concluded that HRIs could produce a relational mechanism that infantilizes users, bringing them back to a stage of imaginary and objectifying intersubjective relationship. The infantilization is caused by a degradation of users ability in frustration management: the interaction with Sexual Robots may bring an objectifying relational setting to intersubjective relations. In fact, users may get used to intersubjective interaction where the other subject is fully available and where there is no need to bargain the drives satisfaction. 
There are some limitations in this work that we would like to point out: first, it deals only with an androcentric perspective on the issue of Sexual Robotics. This is due to the massive presence of gynoid Sexual Robots, while the android versions are far less developed also because of the perceived market demand [34]. The analysis of the relational setting between a Sexual Android and a woman could probably produce a partial reframe of the argument of this paper, while the conclusions could supposedly remain the same.

The second limitation of this paper is that it does not deeply analyse the possibility that Sexual Robots will be fetishized for the very fact that they are not humans. This would bring to a strong reformulation of the symbolic argument and its consequences for this paper. Still, this means that the conclusions of this paper will be limited only to those users who use Sexual Robots as a symbolic substitute of a HHI sexual interaction.

Moreover, this paper dealt mainly with the so-called "symbolic-consequences argument" in analysing the issue of Sexual Robotics. There are many other approaches in the literature on this topic that in this paper are not discussed.

We believe that similar considerations to the ones of this paper can be made for Social Robotics in general, where Sexual Robotics is only a clear example. Next works will deal with the consequences for interaction design of this paper conclusions and will try to extend the object-relation theoretical framework to Social Robotics in general.

\section{References}

1. Sullins, J. P. (2012). Robots, love, and sex: the ethics of building a love machine. In IEEE transactions on affective computing, 3(4), 398-409. https://doi.org/10.1109/T-AFFC.2012.31 
2. Danaher, J. (2017c). Robotic rape and robotic child sexual abuse: should they be criminalised?. Criminal law and philosophy, 11(1), 71-95. https://doi.org/10.1007/s11572-014-9362-x

3. Bendel O. (2017) Sex Robots from the Perspective of Machine Ethics. In: Cheok A., Devlin K., Levy D. (eds) Love and Sex with Robots. LSR 2016. Lecture Notes in Computer Science, vol 10237. Springer, Cham, https://doi.org/10.1007/978-3-319-57738-8_2

4. Levy, D. (2009). Love+ sex with robots: The evolution of human-robot relationships. Duckworth Overlook.

5. Strikwerda, L. (2015). Present and future instances of virtual rape in light of three categories of legal philosophical theories on rape. Philosophy \& Technology, 28(4), 491-510. https://doi.org/10.1007/s13347-014-0167-6

6. Maras, M. H., \& Shapiro, L. R. (2017) Child Sex Dolls and Robots: More Than Just an Uncanny Valley. Journal of Internet Law, 21, 3-17

7. Cox-George, C., \& Bewley, S. (2018). I, Sex Robot: the health implications of the sex robot industry. BMJ Sex and Reproductive Health, 44, 161-164. https://doi.org/10.1136/bmjsrh-2017-200012

8. Gutiu, S. M. (2016). The roboticization of consent. In Robot Law. Edward Elgar Publishing. https://doi.org/10.4337/9781783476732.00016

9. Devlin, K. (2015). In defence of sex machines: why trying to ban sex robots is wrong. The Conversation.

10. Levy, D., \& Loebner, H. (2007). Robot prostitutes as alternatives to human sex workers. In IEEE international conference on robotics and automation, Rome.

11. Sparrow, R. (2017). Robots, Rape, and Representation. International Journal of Social Robotics, 9(4), 465-477. https://doi.org/10.1007/s12369-017-0413-z

12. Danaher, J., McArthur, N. (2017) Robot sex: Social and ethical implications. MIT Press. https://doi.org/10.7551/mitpress/9780262036689.003.0007

13. Coeckelbergh, M. (2010). Robot rights? Towards a social-relational justification of moral consideration. Ethics and Information Technology, 12(3), 209-221. https://doi.org/10.1007/s10676-010-9235-5

14. Drummond A., Sauer J.D., Garea S.S. (2018) The Infamous Relationship Between Violent Video Game Use and Aggression: Uncharted Moderators and Small Effects Make It a Far Cry from Certain. In Ferguson C. (eds). Video Game Influences on Aggression, Cognition, and Attention. Springer, Cham 
15. Ferguson, C. J., Barr, H., Figueroa, G., Foley, K., Gallimore, A., LaQuea, R., ... \& Stevens, J. (2015). Digital poison? Three studies examining the influence of violent video games on youth. Computers in Human Behavior, 50, 399-410.

16. Peeters, A., \& Haselager, P. (2019). Designing virtuous sex robots. International Journal of Social Robotics, 1-12. https://doi.org/10.1007/s12369-019-00592-1

17. Richardson, K. (2016). Sex robot matters: slavery, the prostituted, and the rights of machines. IEEE Technology and Society Magazine, 35(2), 46-53. https://doi.org/10.1109/MTS.2016.2554421

18. Richardson, K. (2015). An Anthropology of Robots and AI: Annihilation Anxiety and Machines. Routledge, New York. https://doi.org/10.4324/9781315736426

19. Richardson, K. 2016a. Technological animism: The uncanny personhood of humanoid machines. Social Analysis, 60(1), 110-128. https://doi.org/10.3167/sa.2016.600108

20. Danaher, J. (2017a) The symbolic-consequences argument in the sex robot debate. In Danaher, J., \& McArthur, N. (Eds.). Robot sex: Social and ethical implications. MIT Press. https://doi.org/10.7551/mitpress/9780262036689.003.0007

21. Van de Poel, I. (2016). An ethical framework for evaluating experimental technology. Science and engineering ethics, 22(3), 667-686. https://doi.org/10.1007/s11948-015-9724-3

22. Summers, F. (2014). Object relations theories and psychopathology: A comprehensive text. Routledge

23. Piaget, J. (2013). The construction of reality in the child. Routledge. https://doi.org/10.4324/9781315009650

24. Fromberg, D. P., \& Bergen, D. (Eds.). (1998). Play from birth to twelve and beyond: Contexts, perspectives, and meanings. Psychology Press

25. Benjamin, J. (2013). The Bonds of Love: Psychoanalysis, Feminism, and the Problem of Domination. Pantheon

26. Bisconti P., Piermattei S. (2020) Sexual Robots: The Social-Relational Approach and the Concept of Subjective Reference. In: Kurosu M. (eds) Human-Computer Interaction. Multimodal and Natural Interaction. HCII 2020. Lecture Notes in Computer Science, vol 12182. Springer, Cham. https://doi.org/10.1007/978-3-030-49062-1_37 
27. Turkle, S., Taggart, W., Kidd, C. D., and Dasté, O. (2006). Relational artifacts with children and elders: The complexities of cybercompanionship. Connection Science 18(4): 347-361. https://doi.org/10.1080/09540090600868912

28. Breazeal, C. L. (2004). Designing sociable robots. MIT press. https://doi.org/10.7551/mitpress/2376.001.0001

29. Winnicott, D. W. (1969). The use of an object. International Journal of PsychoAnalysis, 50, 711-716

30. Sandler, J. (1990). On internal object relations. Journal of the American Psychoanalytic Association, 38(4), 859-880. https://doi.org/10.1177/000306519003800401

31. Ogden, T. H. (1983). The concept of internal object relations. International Journal of Psycho-Analysis, 64, 227-241

32. Winnicott, D. W. (1991). Transitional Objects and Transitional Phenomena. In Playing and reality. Psychology Press

33. Knafo, D. (2015). Guys and dolls: Relational life in the technological era. Psychoanalytic Dialogues, 25(4), 481-502. https://doi.org/10.1080/10481885.2015.1055174

34. Scheutz, M., \& Arnold, T. (2016, March). Are we ready for sex robots?. In 2016 11th ACM/IEEE International Conference on Human-Robot Interaction (HRI) (pp. 351-358). IEEE

35. Watson, L., \& Flanigan, J. (2020). Debating Sex Work. Oxford University Press. 